\title{
Including Pathogen Risk in Life Cycle Assessment of Wastewater Management. Implications for Selecting the Functional Unit
}

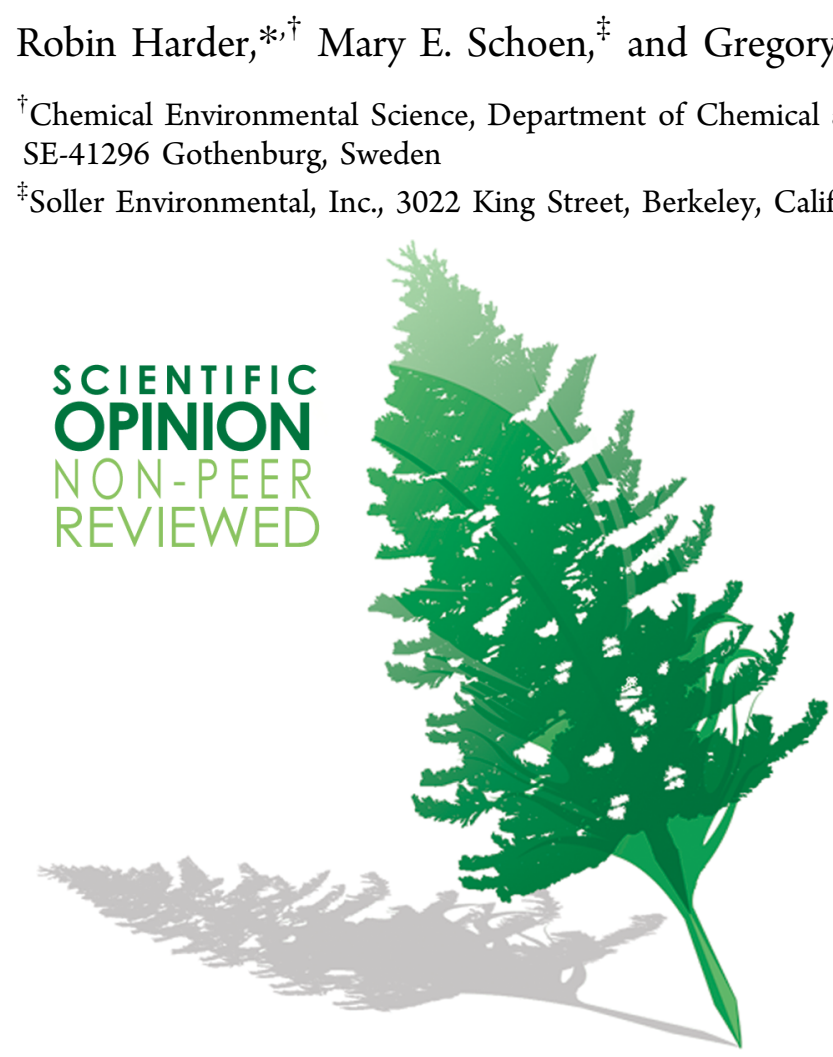

T $\mathrm{n}$ the context of wastewater management, microbial hazards are often addressed in risk assessment (RA) studies ${ }^{1}$ but are at present not routinely included in life cycle assessment (LCA) studies. A recent attempt to include pathogen risk in LCA of wastewater management ${ }^{2,3}$ explored the application of quantitative microbial risk assessment (QMRA) with the intent to compare pathogen risk with other potential impacts on human health. When presented together in an LCA framework, the pathogen risk is treated as an LCA impact category (i.e., category of environmental impact, such as global warming or acidification). This requires that the results obtained through QMRA be scaled to a functional unit, which is not the case in RA studies. The functional unit defines how results are reported using a consistent temporal scale and other assumptions (e.g., carbon dioxide equivalents released per treatment of $10000 \mathrm{~m}^{3}$ wastewater per day during 1 day). In our opinion, the choice of the functional unit for an LCA study that includes a QMRAbased impact category should be carefully considered, as we believe that some functional units are preferable to others.

Let us consider a municipality intending to build a new wastewater treatment plant to serve 30000 persons and treat $10000 \mathrm{~m}^{3}$ wastewater per day on average. An LCA study could be performed in order to identify the wastewater management option with the best environmental performance, thereby also accounting for the overall pathogen health burden associated with the wastewater treatment operations. The input for life cycle impact assessment (LCIA) traditionally consists of emissions from different processes at different locations, which are aggregated and scaled to a functional unit. In conventional LCA impact categories, the emission inventory usually only represents a fraction of the emissions of the contributing processes, and the mathematical relationships usually are linear. However, the pathogen doses in typical QMRA are total doses and the mathematical relationships are nonlinear. Do these differences preclude scaling a QMRA-based impact category to a functional unit?

Let us assume that the QMRA-based impact category for pathogen risk amounts to a total health burden of 3.65 disability-adjusted life years (DALY) per year for a conventional municipal wastewater treatment plant based on all exposure pathways considered. This result, we believe, can very well be scaled to for example 0.01 DALY per treatment of $10000 \mathrm{~m}^{3}$ wastewater per day during $1 \mathrm{day}$, if this were the functional unit of the LCA. In contrast to conventional LCA impact categories, where scaling to a functional unit usually takes places before impact assessment, scaling to a functional unit for the QMRAbased impact category must take place after impact assessment. In other words, irrespective of the functional unit, the underlying calculation of pathogen risk (expressed as health burden) must always be based on the relevant population of people exposed, the pathogen emissions from the full-scale plant, and during the time scales applied in the respective calculation model (QMRA). But, are some functional units preferable to others?

In both water and wastewater management, a QMRA is usually set up with a year as the temporal scope to capture the natural variation in pathogen exposure. A temporal scope of at least a year is also important if cross-connection events that influence the quality of water occur only a small fraction of the time, but have a large overall impact on the annual health burden. ${ }^{1}$ Say the municipality considers a new type of wastewater treatment system with a pathogen health burden of $10^{-3}$ DALY per year, but with all of the exposure occurring during one event with duration of only 1 day, which affects only a small subset (100 people) of the wastewater service population (30000 people). If the pathogen health burden were scaled to match a "per day" functional unit, the health burden would be reported as $2.7 \times 10^{-6}$ DALY per day of operation. However, for the individuals exposed, the associated health burden is zero for 364 days of the year, while for the remaining day, it is $10^{-3}$ DALY per day of exposure. A "per

Received: December 1, 2014

Published: December 22, 2014 
day" functional unit therefore may lead to confusion about the average health burden per day of operation and the typical health burden per day of exposure from these possibly rare but important events. If the pathogen health burden were scaled to match a "per person served" functional unit, the annual health burden would be reported as $3.3 \times 10^{-8}$ DALY per person served. However, for the individuals exposed, the associated annual health burden is $10^{-5}$ DALY. The annual health burden based on a "per person served" functional unit may be misinterpreted as acceptable (e.g., based on a tolerable annual health burden of $10^{-6}$ DALY per individual) while in actuality, the health burden resulting from the operation of the wastewater treatment system is greater than the tolerable health burden since those served are not the same as those exposed.

Although in principle any functional unit can be chosen in LCA, we believe that the inclusion of pathogen risk in LCA through a QMRA-based impact category has implications for the choice of the functional unit. Scaling to a "per day" or "per person served" functional unit may make LCA results prone to misinterpretation. Therefore, scaling to a "per year" and "per service to the community" functional unit may be preferable. Furthermore, analysts should bear in mind that the aggregation of various exposure pathways into one QMRA-based impact category representing the overall pathogen health burden may veil the fact that pathogen risk could still be unacceptable for a certain subset of the population, particularly if overall pathogen risk is small compared to other LCA derived health burdens (where the health burden may be distributed to a larger number of individuals). We would therefore like to emphasize that the integration of a QMRA-based impact category for the inclusion of pathogen risk in LCA should not replace the use of QMRA in an RA framework (i.e., to evaluate the systems under study relative to a tolerable health burden). The kind of perspective that both frameworks can generate should be considered when assessing wastewater management systems.

\section{AUTHOR INFORMATION}

\section{Corresponding Author}

*Phone: +46 (0)31 77229 99; E-mail: robin.harder@chalmers.

se.

\section{Notes}

The authors declare no competing financial interests.

\section{REFERENCES}

(1) Schoen, M. E.; Xue, X.; Hawkins, T. R.; Ashbolt, N. J. Comparative human health risk analysis of coastal community water and waste service options. Environ. Sci. Technol. 2014, 48 (16), 97289736.

(2) Harder, R.; Heimersson, S.; Svanström, M.; Peters, G. M. Including pathogen risk in life cycle assessment of wastewater management. Part 1. Quantitative comparison of pathogen risk to other impacts on human health. Environ. Sci. Technol. 2014, 48 (16), 9446-9453.

(3) Heimersson, S.; Harder, R.; Peters, G. M.; Svanström, M. Including pathogen risk in life cycle assessment of wastewater management. Part 2. Quantitative comparison of pathogen risk to other impacts on human health. Environ. Sci. Technol. 2014, 48 (16), 9338-9445. 